\title{
Estimating the prevalence of drug misuse in Dundee, Scotland: an application of capture-recapture methods
}

\author{
Gordon Hay, Neil McKeganey
}

\begin{abstract}
Study objectives - To apply capturerecapture methods to provide an estimate of the prevalence of opiate and benzodiazepine misuse in Dundee, Scotland.

Design - A four sample capture-recapture method using data from both statutory and non-statutory data sources to estimate drug misuse prevalence in Dundee between January 1990 and December 1994. Participants - Users of benzodiazepines or opiates residing within Dundee.

Results - Altogether 855 drug misusers were identified from various sources within Dundee; many were identified from more than one source. Using this data, the estimated unknown population was 1702 , giving a total population of 2557 (95\% confidence interval (CI) 1974, 3458) who misuse benzodiazepines or opiates. This represents a prevalence of 28.8 (95\% CI 22.3 , 39.0) per thousand.

Conclusions - Capture-recapture techniques can be applied to statutory and non-statutory agency data to produce an estimate of at least certain sections of the drug misusing population. However, it is important to recognise the limitations of this methodology and in future to seek to combine a range of approaches to the problem of estimating prevalence rather than sticking rigidly to any single approach.
\end{abstract}

(F Epidemiol Community Health 1996;50:469-472)

With the publication of the Government white paper Tackling Drugs Together, ${ }^{1}$ considerable emphasis has been placed upon providing an estimate of the prevalence of drug misuse within the UK. Information in this area is clearly of value at both a national and a local level with respect to drug misuse monitoring and the planning of services to drug misusers. Despite the importance of such information, establishing the prevalence of drug misuse is a far from easy task. There has never been a national survey of drug misuse within the UK and while there have been a number of calls for such a survey to be carried out it is questionable whether accurate prevalence information on drug misuse can be obtained using that method alone given the combined problems of under reporting and non-response which such a survey would undoubtedly be subject to. The limitations of the official Home Office addict notification system ${ }^{2}$ in presenting an accurate picture of drug misuse prevalence are well understood. Although such official information has been supplemented by the creation of regional drug misuse databases ${ }^{3}$ which record the number of new notifications, in the absence of some assessment of how complete these databases are, care must be taken in drawing inferences from such official data as to the prevalence of drug use within the UK. ${ }^{4}$ The lack of completeness in the official drug using notification systems has often been compensated for in the past by applying a multiplier to the known drug using population to estimate the size of the unknown population. ${ }^{56}$ However considerable uncertainty remains as to the size of the multiplier to apply and whether the same figure can be applied across a diverse range of areas.

More recently, interest has been expressed in the application of capture-recapture techniques to estimate drug use prevalence. Indeed in a recent editorial in the British Medical fournal, LaPorte has suggested that capturerecapture methodology may bring about a 'paradigm shift in how counting is done in all the disciplines that assess human populations'. ${ }^{7}$ The following debate, however, suggested that more evidence may be needed as to the use of such techniques. ${ }^{8-10}$ Capturerecapture methods have previously been used to correct for under reporting of prevalence of diseases such as spina bifida ${ }^{11}$ and cancer. ${ }^{12}{ }^{13}$ Recent research has attempted to employ these methods in estimating the prevalence of drug injecting in Glasgow, ${ }^{14}{ }^{15}$ and drug use in Liverpool $^{16}$ and areas of other countries worldwide. ${ }^{17-19}$ Capture-recapture methods have also recently been applied to estimate the prevalence of street prostitution within Glasgow $^{20}$ and the number of homeless people within a London borough. ${ }^{2}$

In this paper we describe our attempts at utilising capture-recapture methodology to estimate drug misuse prevalence within Dundee, using both official data sources and non-statutory data sources. Although the official data recording systems may be inadequate in their own right at providing an estimate of drug use prevalence, their utilisation along with non-statutory recording systems within a capture-recapture analysis may enable such an estimate to be produced.

\section{Methods}

The data from this study were obtained from four sources which collect data on drug misusers in Dundee. Although previous studies have 
Table 1 Drugs used and injected in a six month time period by a sample of 274 drug injectors residing in Tayside. Data from the Tayside behavioural and seroprevalence study

\begin{tabular}{lrc}
\hline Drug & Used & Injected \\
\hline Heroin & 76 & 62 \\
Cocaine & 50 & 22 \\
Methadone (street) & 184 & 9 \\
Methadone (prescribed) & 204 & 9 \\
Methadone (tablets) & 111 & 49 \\
Dihydrocodeine & 188 & 49 \\
Buprenorphine & 92 & 68 \\
Dipipanone & 153 & 134 \\
Dextromoramide & 30 & 27 \\
Morphine & 82 & 48 \\
Dextropropoxyphene & 67 & 3 \\
Triazelam & 26 & 5 \\
Temazepam & 210 & 76 \\
Diazepam & 220 & 54 \\
Amphetamine & 168 & 119 \\
MDMA† & 100 & 18 \\
Crack cocaine & 19 & 5 \\
\hline
\end{tabular}

${ }^{\star}$ Haw and Higgins, unpublished manuscript.

tDrug users who were solely identified as using only these drugs were excluded by the study definition from the target population

Table 2 Summary of data collected, in a contingency table which denotes presence or absence from four data sources of 855 drug misusers

\begin{tabular}{|c|c|c|c|c|c|c|}
\hline & & $D P C$ & Present & Present & Absent & Absent \\
\hline$H I V$ & $P O L$ & $I S D$ & Present & Absent & Present & Absent \\
\hline Present & Present & & 0 & 1 & 0 & 1 \\
\hline Present & Absent & & 2 & 12 & 1 & 29 \\
\hline Absent & Present & & 6 & 14 & 4 & 50 \\
\hline Absent & Absent & & 60 & 600 & 75 & - \\
\hline
\end{tabular}

HIV - Tayside HIV test register; POL - Police; DPC - The Dundee Drug Problem Centre; ISD - The Scottish drug misuse database held by the Information and Statistics Division of the Scottish Health Service.

attempted to estimate the prevalence of drug injecting, we have found that it was not possible to create a screening instrument to identify drug injectors from at least one of our data sources. Table 1 presents some of the results from a concurrent study into behavioural aspects of drug injectors.

It is clear from these data that not only are a wide range of drugs used within Dundee, but also that the same drugs are subject to both injecting and non-injecting use. Therefore it cannot be inferred that a drug user is an injector simply from knowledge of the drugs he or she is using. We base our estimate on the number of people that use benzodiazepines or opiates, drugs which are commonly injected in Dundee. Amphetamine sulphate is also commonly injected in Dundee, although the more general patterns of use for this drug necessitate different methods for estimating the number of

Table 3 Demographic characteristics of drug misusers identified from our four data sources in Dundee

\begin{tabular}{lccl}
\hline & Known drug users & $\begin{array}{l}\text { Population of Dundee } \\
\text { (from 1991 census) }\end{array}$ & $\begin{array}{l}\text { Prevalence (per } \\
\text { thousand) }\end{array}$ \\
\hline Males (all ages) & 614 & 42885 & 14.3 \\
$15-24$ & 176 & 11392 & 15.4 \\
$25-34$ & 337 & 11906 & 28.3 \\
$35-44$ & 92 & 10431 & 8.8 \\
$45-54$ & 9 & 9156 & 1.9 \\
Females (all ages) & 234 & 45630 & 5.1 \\
$15-24$ & 66 & 11845 & 5.6 \\
$25-34$ & 123 & 13034 & 9.4 \\
$35-44$ & 37 & 11078 & 6.8 \\
$45-54$ & 7 & 9673 & 0.7 \\
Total (both sexes) & 848 & 88515 & 9.6 \\
\hline
\end{tabular}

users, both injectors and those who use amphetamines recreationally. Data were collected over a five year period, from January 1990 to December 1994 . We summarise below the data sources used in this analysis:

\section{DATA SOURCES}

Dundee Drug Problem Centre

This drug dependence unit provides a counselling and substitute prescribing service for drug misusers in Tayside Region. Client case notes and admission assessment schedules were reviewed to establish the pattern of each individual's drug use. There were 695 individuals who satisfied the criteria for inclusion in the study.

\section{Tayside HIV register}

This register, held by Tayside Health Board, lists all known subjects within Tayside Region who are HIV positive. Using the reported transmission category and postcode data we obtained a subset of 46 drug misusers living in Dundee.

\section{Scottish drug misuse database}

The Information and Statistics Division of the Scottish Health Service collects data on new problem drug users seen at a broad range of services across Scotland. ${ }^{3}$ Although the Dundee Drug Problem Centre submits forms which are used in this database, we have used only data from forms submitted by general practitioners in Dundee. Thus, we included 147 individuals from this database.

\section{Misuse of Drugs Act}

Tayside Police hold data on all persons arrested under the Misuse of Drugs Act (1971). Most of these offences included only cannabis or other drugs which we have excluded from this study, leaving data on 76 individuals.

\section{Results}

THE OBSERVED SAMPLE

Date of birth, sex, and initials were used to identify individuals who were in more than one data source, hence we identified 855 individuals from the 964 data records. We summarise the data in table 2 . Table 3 presents some demographic characteristics of the identified drug users. Ignoring the hidden population of drug users, 9.6 per thousand of the population aged between 15 and 54 were identified as drug users. This compares with 4.6 per thousand of the population of the same age in Glasgow in 1990 who were known to be drug injectors and 5.9 per thousand in the same age category that were identified as opiate or cocaine users in Liverpool in 1991. The mean (SD) age of the drug users identified from the above data sources was 28.9 (6.9) years. The male:female ratio from these data was 2.6:1. No inference can be drawn about the age distribution or male:female ratio of the total population from these data.

CAPTURE-RECAPTURE ANALYSIS

Log-linear models are commonly used to describe data from contingency tables, and such models can be fitted using the statistical 
Table 4 Results from log-linear analysis

\begin{tabular}{llrrrr}
\hline Model & Interactions present & \multicolumn{1}{c}{$\chi^{2}$} & $d f$ & $p$ value & Estimate \\
\hline 1 & None & 17.50 & 10 & 0.06 & 971 \\
2a & ISD and POL & 9.00 & 9 & 0.44 & 1451 \\
2b & ISD and DPC & 15.04 & 9 & 0.09 & 1014 \\
2c & ISD and HIV & 17.31 & 9 & 0.04 & 963 \\
2d & DPC and POL & 12.47 & 9 & 0.19 & 822 \\
2e & DPC and HIV & 16.77 & 9 & 0.05 & 927 \\
2f & POL and HIV & 17.48 & 9 & 0.04 & 972 \\
3a & ISD and DPC; ISD and POL & 3.75 & 8 & 0.88 & 1702 \\
3b & ISD and DPC; ISD and HIV & 9.00 & 8 & 0.34 & 1453 \\
3c & ISD and DPC; DPC and POL & 8.52 & 8 & 0.38 & 1268 \\
3d & ISD and DPC; DPC and HIV & 8.80 & 8 & 0.36 & 1539 \\
3e & ISD and DPC; POL and HIV & 8.84 & 8 & 0.36 & 1470
\end{tabular}

ISD - Scottish drug misuse database, POL - Police, DPC - Dundee Drug Problem Centre, HIV - Tayside HIV test register

package $G L I M .^{22}$ These models can be created using the values in table 3 and then used to provide an expected value for the cell which is unobserved, that is, the number of unidentified drug misusers. As in linear regression models, using a model to obtain an estimate away from the observed values which were used to create the model, that is extrapolating, should be done with care. In this analysis, the factors will be presence or absence in each of the four sources and the dependent variable will be the series of counts. Interactions between factors can be included in the model, and the criteria for selecting which interactions should be included are based on the deviance, which is a measure of how well the expected values match the observed values. Once an adequate model has been selected, the expected number for the unknown cell can be extracted and the likelihood interval method ${ }^{23}$ can be used to obtain an associated confidence interval.

UNOBSERVED POPULATION

A range of models was fitted to the observed values. All models with one interaction term and a subset of models with two interaction terms are listed in table 4. From this table models which include an interaction between the Scottish drug misuse database sample and the Dundee Drug Problem Centre sample fit the observed data, and a model which additionally includes an interaction between the Scottish drug misuse database and the Police sample fits the data well. If this model is used, we can estimate the number of drug misusers not known to any data source as 1702 (95\% confidence interval (CI) 1119, 2603), and therefore the total number of drug misusers will be 2557 (1974 to 3458). The prevalence per thousand of the population aged 15 to 55 will be 28.8 (22.3-39.0). We note that the ratio of identified to unidentified was found to be 1:1.99.

\section{Discussion}

MODEL SELECTION

We can only present a few of the models that we have used in obtaining an estimate for opiate and benzodiazepine use in Dundee. To reduce heterogeneity in the drug using population, we focused on these drugs, in particular excluding amphetamine users as the patterns of use of this drug differ from those of other injectable drugs. Another way of attempting to reduce heterogeneity would be to run equivalent models in relation to sex or age group. This was carried out, although it did not result in any major difference in the model. This may be partly due to the small numbers in some of the resultant cells. Little is known about the complex relationships between the data sources used in this study, thus we have no strong prior belief that a particular interaction should be present. The main interaction term in the model may be due to cross referrals to the drug problem centre from GPs who then notify the regional drug misuse database, although care must be taken in attaching explanations to interactions after the model has been created. The results from this study are broadly consistent with a concurrent study of HIV in the drug injecting community. ${ }^{24}$

\section{LIMITATIONS}

There are several points that should be considered when using capture-recapture methodology to estimate the size of a drug misusing population. ${ }^{25}$ It is important to include a discussion of these considerations lest the current pressure to provide estimates of drug misuse prevalence lead to a rather uncritical acceptance of those methods which appear to be able to provide these estimates. All the data sources we have used collate data over a considerable time period, hence there may be people included in this study who have either stopped misusing drugs or have moved out of the area of interest. While log-linear models can be developed to describe these open populations, this would involve increasing the complexity of the models produced perhaps to the point of removing understanding of the estimate. Larson ${ }^{17}$ notes, however, that violation of the closed population assumption will not seriously effect the estimate. Additional data were collected from the drug problem centre sample from which the length of time an individual had been using drugs other than cannabis could be estimated. The mean (SD) length of such drug use was 10.5 (5.8) years, which suggests that most individuals identified as drug users over the four year time period would currently be drug users. It is not possible, however, to correct the estimate for those individuals that may have stopped using drugs over the study period. The likely effect of this would be to overestimate the total population size. As the data sources employed in this analysis are more likely to include long term or problematic drug misusers, we may be excluding young drug users and those who have not yet experienced problems due to prolonged drug misuse. The estimates obtained from capture-recapture analysis must be considered in conjunction with relevant confidence intervals. Such confidence intervals are valid only for the particular model chosen to describe the data. As model selection can be subjective, particularly when many data sources are used and many different interactions can be included, the confidence interval must be interpreted with care. ${ }^{26}$ 


\section{Conclusion}

Most drug misuse research within Scotland has focused upon either Edinburgh ${ }^{27}$ or Glasgow $^{29}{ }^{30}$ the former because of concerns in relation to HIV, and the latter because of the size of the drug injecting population that has been identified. As a result of this focus upon these two cities we know much less about the extent and nature of drug misuse more broadly within Scotland. On the basis of the above estimate, injectable drug use in Dundee is on a par with Glasgow, where the prevalence of drug injecting in 1990 was estimated at 13.5 per thousand aged 15 to $55,,^{15}$ although a direct comparison of the figures may not be relevant as the Glasgow figure refers to drug injecting and the Dundee figure refers to the use of opiates and benzodiazepines.

It is clearly possible, with careful use, to combine both official and non-statutory data to produce an estimate of drug misuse prevalence. The question remains, however, whether capture-recapture methods are a better way of producing a prevalence estimate than a national survey. Under reporting and non-response are major problems facing the use of a survey approach to produce such prevalence information; equally there have been no attempts to produce a national prevalence estimate on the basis of such capturerecapture analysis. To date, capture-recapture methods have been applied to a relatively small number of largely urban centres such that their applicability within more rural environments remains unproved.

Instead of thinking in terms of a single best approach at producing an estimate of drug misuse prevalence, we need to be more sophisticated in tailoring our choice of method to the specific nature of the population whose prevalence we are seeking to estimate. Combining different methods to estimate drug misuse prevalence will undoubtedly present further new challenges, but may be a more realistic way of tackling the problem than a dogmatic adherence to any single method.

The Centre for Drug Misuse Research is funded by the Chief Scientist Office of the Scottish Home and Health Department. The opinions expressed in this paper are not necessaril ment. The opinions expressed in this paper are not necessarily those of the Scottish Home and Health Department. We are
grateful to the many people who have aided this study by giving grateful to the many people who have aided this study by giving us access to relevant data: Elaine Buist of the Information and Statistics Division of the Scottish Health Service, Dr David Bell and Carole Robertson of Tayside Health Board, Detective Inspector Fiona Clacher and the crime management team of
Tayside Police, and Dr Brian Johnston, Dina Ajeda and the staff Tayside Police, and Dr Brian Johnston, Dina Ajeda and the staff
of the Dundee Drug Problem Centre. We should also like to of the Dundee Drug Problem Centre. We should also like to acknowledge the help and encouragement given by Sally Haw and Kathryn Higgins of the Tayside behavioural and HIV seroprevalence study and Karl Stern and Jill Lewis of Tayside Region Social Work Department. Eleanor Gallagher much of the clerical task of accessing data from a number of these agencies. We are grateful to Professor Richard Cormack for providing advice in the preparation of this paper.

1 Home Office. Tackling drugs together. A consultation document for England 1995-1998. London: HMSO, 1994.
2 Home Office. Misuse of drugs act, London: HMSO, 1971.

3 Information and Statistics Division, The National Health Service in Scotland. Scottish drug misuse database bulletin Service in Scotland. Scottish drug misuse
1994. Edinburgh: ISD Publications, 1994.

4 Sutton M, Maynard A. Are drug policies based on 'fake' statistics? Addiction 1993;8:455-8.

5 Parker H, Bakx K, Newcombe R. Living with heroin: the impact of a drugs epidemic on an English community. Milton Keynes: Open University Press, 1987.

6 Hartnoll R, Mitcheson M, Lewis R, Bryer S. Estimating the prevalence of opioid dependence. Lancet 1985;i:203-5.

7 LaPorte RE. Assessing the human condition: capturerecapture techniques. BMF 1994;308:5-6.

8 Gutteridge W, Collin C. Capture-recapture techniques quick and cheap. BMf 1994;308:531

9 Waters WE. Capture-recapture techniques - more unreliable in humans than birds. BMF 1994;308:531.

10 Black JFP, McLarty DG, Mtasiwa D. Capture-recapture techniques - difficult to use in developing-countries. $B M \mathcal{F}$ 1994;308:531.

11 Hook E, Albright S, Cross P. Use of bernoulli census and log-linear methods for estimating the prevalence of spin bifida in livebirths and the completeness of vital records in New York State. Am F Epidemiol 1980;112:750-8.

12 Schouten L, Straatman H, Kiemeney L, Gimbrere C Verbreek A. The capture-recapture method for estimation of cancer registry completeness - a useful tool. Int $₹$ Epidemiol 1994;23:1111-6.

13 Robles SC, Marret D, Clarke EA, Risch HA. An application of capture-recapture methods to the estimation of th completeness of cancer registration. $\mathcal{f}$ Clin Epidemiol. 1988;41:495-501.

14 Frischer $M$. Estimated prevalence of injecting drug use in Glasgow. Br f Addict 1992;87:57-66.

15 Frischer M, Leyland A, Cormack R, et al. Estimating the population prevalence of injection drug use and infection with Human Immunodeficiency Virus among injection drug users in Glasgow, Scotland. Am $\underset{f}{\text { Epidemio }}$ $1993 ; 138: 170-81$.

16 Squires NF, Beeching NJ, Schlecht BJM, Ruben SM. An estimate of the prevalence of drug misuse in Liverpool and a spatial-analysis of known addiction. $\mathcal{F}$ Public Health Med 1995;17:103-9.

17 Larson A, Stevens A, Wardlaw G. Indirect estimates of hidden populations - capture-recapture methods to estimate the numbers of heroin users in the Australian Capital Territory. Soc Sci Med 1994;39:823-31.

18 Mastro TD, Kitayaporn D, Deniger BG, et al. Estimating the number of HIV-infected injection-drug users in Bang kok - a capture-recapture method. Am $\mathcal{f}$ Public Health 1994;84:1094-9.

19 Domingosalvany A, Hartnoll RL, Maguire A, Suelves JM, Anto JM. Use of capture-recapture to estimate the prevalence of opiate addiction in Barcelona, Spain, 1989. Am $f$ Epidemiol 1995;141:567-74.

20 McKeganey N, Barnard M, Leyland A, Coote I, Follet E. Female streetworking prostitution and HIV infection in Glasgow. BMF 1992;305:801-4.

21 Fisher N, Turner SW, Pugh R, Taylor C. Estimating numbers of homeless and homeless mentally ill people in north east Westminster by using capture-recapture analysis. BMF 1994;308:27-30.

22 Francis B, Green M, Payne C, eds. The GLIM System, release 4. Oxford: Clarendon, 1994.

23 Cormack $R$. Interval estimation for mark-recapture studies of closed populations. Biometrics 1992;48:567-76.

24 Haw SJ, Higgins KM, Bell D, Johnston BB, Richardson AM. Evidence of continuing risk of HIV transmission among injecting drug users from Dundee. Scot Med $\mathscr{f}$ 1996;41:3-4

2525 Watts $\mathrm{CH}$, Zwi AB, Foster G. Using capture-recapture in prom

26 Regal RR, Hook EB. The effects of model selection on confidence-intervals for the size of a closed population. Stat Med 1991;10:717-2

27 Robertson JR, Ronald PJM, Raab GM, Ross AJ, Parpia T. Deaths, HIV-infection, abstinence, and other outcomes in a cohort of injecting drug-users followed up for 10 years. $B M F$ 1994;309:369-72

28 Davies AG, Dominy NJ, Peters A, Bath GE, Burns SM, Richardson AM. HIV in injecting drug-users in Edinburgh - prevalence and correlates. F Acquir Immune Defic Syndr - prevalence and correlates. $\mathcal{F}$ A

29 McKeganey N, Barnard M. Lives in the balance: AIDS drug and sexual risk. Buckingham: Open University Press, 1992.

30 Frischer M, Bloor M, Goldberg D, Clark J, Green S, McK eganey N. Mortality among injecting drug users: a critical reappraisal. $\mathcal{F}$ Epidemiol Community Health 1993;47:59-63. 